\title{
A tribute to Morton Meyers, MD
}

\author{
C. Daniel Johnson \\ Department of Radiology, Mayo Clinic, Scottsdale, AZ 85259, USA
}

Dr. Morton Meyers will step down as Editor-in-Chief of Abdominal Imaging on January 1, 2014. He leaves behind a legacy of excellence in both his own professional career as a Radiologist and as Editor-in-Chief of Abdominal Imaging.

Dr. Meyers founded the quarterly journal Gastrointestinal Radiology in 1976. In 1993 he expanded its focus to include gastrointestinal imaging, genitourinary imaging, and interventional abdominal radiology. The expanded journal was renamed Abdominal Imaging, and it became a bimonthly publication in 1994. This Journal change forecasted the need to remain competent in both gastrointestinal and genitourinary radiology, long before many of us recognized this clinical practice imperative.

Dr. Meyer's quest for excellence is attested by the Journal's progressively rising impact factor. The impact factor increased $57 \%$ over the past 5 years to a current 1.905. Each annual volume is comprised of $1300-1500$ pages. The numbers of submissions have increased $20 \%$ over the past 2 years. The acceptance rate is now approximately $20 \%$. Accepted articles are published online within 2-3 weeks (the official date of publication), and the print issue some months later. Innovations of the Journal include a wide range of articles on state-of-theart topics and feature sections that focus on a single theme with 5-7 contributions under the guidance of a guest editor.

The journal enjoys the support of many international abdominal, gastrointestinal and genitourinary societies. The international reach of the Journal is highlighted by a distinguished international editorial board, and global representation throughout the table of contents of every issue. Recently, with the merger of the Society of Gastrointestinal Radiology (SGR) and the Society of Uroradiology (SUR) into the Society of Abdominal Radiology (SAR), the Journal has been named the official Journal of the SAR.

Dr. Meyers is very humble about his contributions to the Journal. He notes that, "I take pride in having nurtured the journal over almost four decades to its current stature as a prestigious international forum." The abdominal imaging community in radiology is extremely grateful to him for his legion efforts, and for his immense contributions to the Journal and to the field of Abdominal Imaging. Our words of praise and thanks seem inadequate to such a pioneer and giant in Radiology. 